\title{
KARAKTERSITIK ZAT WARNA TERMOKROMIK TOUCH ACTIVATED DAN HASIL PENCAPANNYA PADA KAIN KAPAS
}

\author{
CHARACTERISTICS OF THE TOUCH-ACTIVATED \\ THERMOCHROMIC DYE AND ITS PRINTING RESULTS ON THE \\ COTTON FABRIC
}

\author{
Ida Nuramdhani ${ }^{1}$, Nurfadilah Ikhsani²) \\ 1 Politeknik STTT Bandung, Bandung, 40272, Indonesia, \\ 2 Politeknik STTT Bandung, Bandung, 40272, Indonesia. \\ E-mail:
}

\begin{abstract}
ABSTRAK
Zat warna termokromik, yang dikategorikan sebagai salah satu jenis smart dyes, dikembangkan terutama untuk memperoleh aspek-aspek fungsional pada bahan tekstil melalui kemampuannya untuk merespon rangsangan tertentu. Zat warna termokromik jenis touch activated dapat memudar warnanya ketika disentuh (pada suhu $<29^{\circ} \mathrm{C} / 84^{\circ} \mathrm{F}$ ). Kebutuhan untuk melengkapi informasi mengenai aspek-aspek teknis aplikasi dan karakteristik zat warna termokromik komersial jenis touch activated mendorong dilakukannya penelitian ini. Penelitian dilakukan dengan mengaplikasikan zat warna tersebut pada kain kapas dengan metode pencapan. Perbandingan zat warna:binder sebesar 1:1 dan diikuti dengan fiksasi pada temperatur ruang selama 30 menit. Hasil analisa FTIR menunjukkan bahwa zat warna tersusun atas senyawa organik aromatik dengan beberapa puncak serapan yang dominan seperti $\mathrm{C}=\mathrm{O}, \mathrm{C}=\mathrm{C}$, dll. Kain hasil pencapan memudar setelah menerima rangsangan sentuhan dan bersifat reversibel. Perbedaan usia dan jenis kelamin responden yang melakukan stimulus sentuhan tidak berpengaruh secara signifikan pada waktu retensi respon perubahan warna kembali. Ketahanan luntur warna kain hasil pencapan terhadap pencucian cukup rendah (nilai staining scale mencapai 2-3). Zat warna termokromik jenis touch activated lebih tepat digunakan untuk kepentingan teknis dan estetis pada aplikasi di bidang garmen atau untuk aplikasi sensor dan sejenisnya.
\end{abstract}

Kata kunci: zat warna termokromik, touch activated, leuco type, pencapan

\begin{abstract}
Thermochromic dyes, which are classed as one of what so-called smart dyes, have been developed specially to give functional effects on the textile materials through their capability to sense a particular given stimulus. The touch activated type of thermochromic dyes could change their color when touched (at $T<29^{\circ} \mathrm{C} / 84^{\circ} \mathrm{F}$ ). This research was carried out in order to complete the technical information about how to apply the commercial thermochromic dyes on the textile fabric and the characteristics of the printing results. The dye was printed to $100 \%$ cotton fabric with
\end{abstract}


the dye:binder ratio of 1:1. Fixation was carried out at the room $T$ for 30 minutes. TIR spectra showed that the dyes were composed of aromatic organic compunds with several important peaks along the spctra curve like $C=O, C=C$, etc. The printed color got pale or disappear after being touched and the maximum wavelength was shifted to the direction of $400 \mathrm{~nm}$. The dyes were reversible. In the manual analysis of time retention, differences of age and sex of the respondents did not significantly affect the color-changing responses of the dyes. The fastness to washing of the printed color was low (staining scale of 2-3). The dyew were more appropriate to be used for technical and aesthetical purposes in the area of garment fashion or for any applications of sensors.

Keywords: thermochromic dyes, touch activated, leuco type, printing

\section{PENDAHULUAN}

Dalam industri tekstil konvensional, zat warna merupakan salah satu komponen penting dalam proses pewarnaan, baik untuk aplikasi dengan cara pencelupan maupun pencapan (Talvenmaa dkk., 2010). Secara prinsip, zat warna digunakan untuk memberikan efek pewarnaan terhadap bahan tekstil dengan parameterparameter kualitas yang diinginkan, misalnya arah dan ketuaan warna tertentu, kerataan hingga ketahanan luntur warna yang harus dicapai. Dalam pengembangannya, kriteria hasil pewarnaan tekstil mengalami pergeseran-pergeseran seiring dengan perkembangan di berbagai bidang. Pewarnaan tekstil saat ini tidak lagi digunakan untuk memperoleh efek teknis dan estetis saja, namun juga untuk memperoleh aspek-aspek fungsional hingga memberikan efek kecerdasan terhadap bahan tekstil yang dihasilkan. Diantara contohnya adalah zat warna yang memiliki kepintaran dalam merespon rangsangan dari luar dengan berbagai bentuk, misalnya paparan cahaya pada panjang gelombang tertentu, jenis pelarutannya, $\mathrm{pH}$, hingga sentuhan dan temperatur lingkungannya. Respon yang diberikan biasanya berupa perubahan warna. Zat warna yang memiliki kemampuan seperti itu disebut zat warna kromik (Peter Bamfied dan Michael G Hutching, halaman 48., 2010, Khattab dkk, 2011). Sebutan spesifik untuk zat warna kromik berbeda-beda, bergantung pada jenis rangsangannya, contohnya fotokromik, halokromik, dan termokromik untuk zat warna yang dapat berubah warna masing-masing 
karena paparan cahaya, perubahan $\mathrm{pH}$, dan perubahan temperatur. Sejalan dengan berkembangnya teknologi tekstil maju, termasuk diantaranya tekstil cerdas (smart textiles), zat warna kromik telah menjadi daya tarik tersendiri bagi para peneliti untuk dikembangkan sebagai smart dyes untuk diaplikasikan di berbagai bidang dalam beberapa tahun terakhir ini, hingga beberapa telah diproduksi secara komersial. Diantara yang telah banyak dikenal secara komersial adalah jenis fotokromik dan termokromik. Bahanbahan tersebut telah menarik perhatian para pelaku industri fesyen yang karena keunikannya dapat meningkatkan nilai kualitas dan ekonomi produk fesyen yang dihasilkan (Tang, S.L.P., 2006). Selain itu, kemampuan berubah warna tersebut telah menarik perhatian pula untuk dimanfaatkan secara fungsional seperti untuk sensor, terutama ketika perubahan tersbut dapat dikontrol dan dapat kembali ke warna asalnya (Talvenmaa dkk., 2010).

Zat warna termokromik adalah zat warna yang dapat merespon perubahan suhu dengan cara perubahan warna. Jenis zat warna termokromik dibagi menjadi dua jenis, yaitu reversibel atau warna kembali dan irreversibel atau warna tidak kembali. Termokromik reversibel yang telah banyak digunakan untuk tekstil adalah zat warna termokromik yang berbasis leuko dan kristal cair. Zat warna termokromik jenis pewarna leuko pada umumnya berubah dari berwarna menjadi tidak berwarna atau berwarna lain dengan peningkatan suhu. Kristal cair menunjukkan 'permainan warna' dengan melewati seluruh spektrum dengan peningkatan suhu. Dalam pengaplikasiannya, zat warna termokromik memerlukan substrat yang berhubungan dengan sistem penghasil panas misalnya melibatkan kontak kulit manusia atau sirkuit elektronik (Robert M dkk,. 2007). Telapak tangan merupakan bagian tubuh yang terdiri dari pembuluh darah yang banyak, sehingga pada bagian ini suhunya menjadi lebih tinggi dibandingkan dengan suhu pada bagian tubuh. Zat warna termokromik jenis touch activated merupakan zat warna yang akan berubah warna saat disentuh atau digosok. Warna akan hilang atau memudar ketika digosok atau disentuh, sehingga warna lain di bawahnya akan muncul (warna pudar 
pada suhu $29{ }^{\circ} \mathrm{C} / 84^{\circ} \mathrm{F}$ ). Zat warna tersebut bersifat tidak larut dalam air dan tidak memiliki afinitas terhadap serat alam maupun serat sintetis ( $D$ Aitken, 1996). Pengaplikasiannya didasarkan pada pelekatan zat warna menggnakan binder, sehingga tidak ada ikatan kimia antara zat warna dengan serat. Gambar 1 menunjukkan ilustrasi perubahan warna pada zat warna termokromik jenis touch activated sebelum dan sesudah disentuh.

i

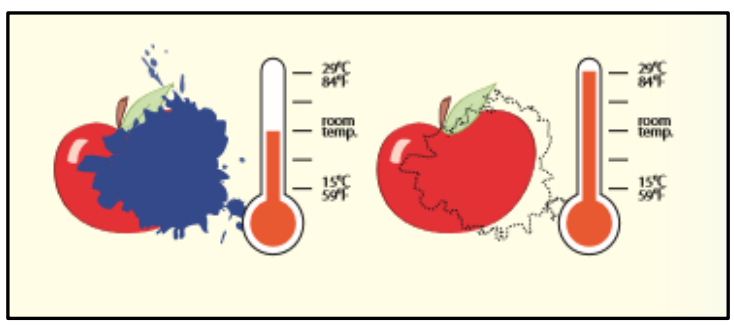

Sumber : Thermochromic Leuko Dye

Test Kit Users Guide - LCR Hallcrest : 2019

Gambar 0. Ilustrasi Perubahan Warna pada Zat Warna Termokromik Jenis Touch Activated Sebelum dan Setelah Sentuh

Gambar 1 menunjukkan bahwa pada temperatur ruang terlihat motif apel berwarna merah serta motif percikan yang berwarna biru. Warna merah tersebut menggunakan warna konvensional, sedangkan warna biru merupakan zat warna termokromik jenis touch activated. Ketika motif yang berwarna biru tersebut digosok atau disentuh hingga suhunya sekitar $29^{\circ} \mathrm{C}$, maka warna biru memudar sampai menghilang. Dari penjelasan tersebut dapat disimpulkan bahwa pigmen termokromik jenis touch activated akan memudar bahkan menghilang ketika diberi sentuhan atau gosokan.

Faktor penting dalam pengaplikasian zat warna termokromik jenis touch activated pada kain kapas yaitu suhu ruang saat proses pengaplikasian berlangsung, sensitifitas suhu serta sifat pigmen warna (Marjan Kooroshnia., 2013). Pada dasarnya pigmen termokromik dapat berubah warna saat ada pengaruh suhu yang karena struktur molekul pigmen termokromik tersebut tidak stabil, sehingga struktur molekul berubah membentuk kromofor baru saat terkena suhu. Hal tersebut yang menyebabkan warna berubah. Gambar 2 merupakan contoh stuktur kimia zat warna termokromik jenis touch activated. 


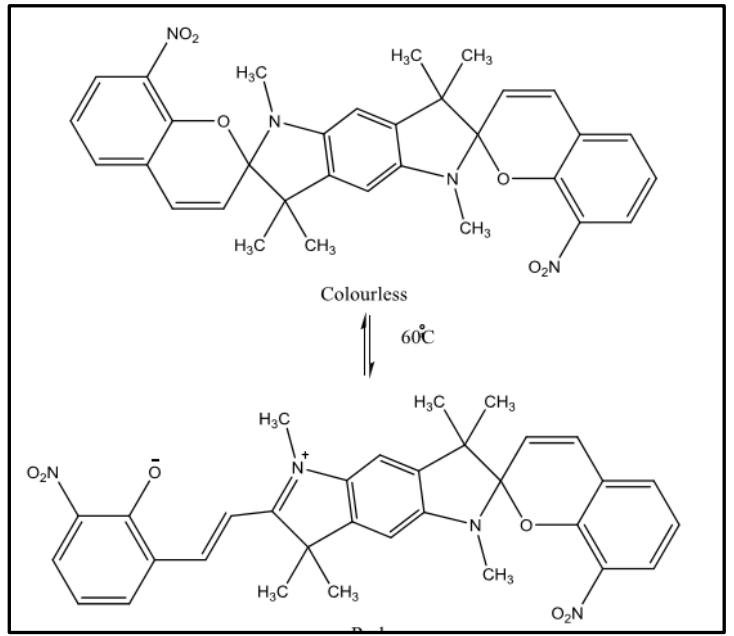

Sumber : Jurnal Waseem Ibrahim, Heriot-Watt University School of Textiles and Design, Augustus : 2012

Gambar 2. Struktur Molekul Zat Warna

Termokromik Jenis Touch Activated

Penelitian mengenai termokromik cukup menarik perhatian dalam satu hingga dua dekade terakhir. Namun demikian, belum banyak publikasi mengenai termokromik jenis touch activated yang dibahas secara khusus. Di sisi lain, produk tersebut telah dapat diperoleh di pasaran sebagai bahan komersial yang dapat digunakan dalam berbagai aplikasi. Untuk melengkapi informasi mengenai teknik aplikasi dan karakterisasi hasil pewarnaan menggunakan termokromik komersial jenis touch activated, penelitian ini dilakukan. Tujuan utamanya adalah untuk menganalisis karakteristik zat warna termokromik komersial jenis touch activated dengan cara mengaplikasikannya pada kain kapas $100 \%$ dengan metode pencapan serta mengevaluasi sifat-sifat hasil pencapannya. Karena sifanya yang sangat peka terhadap panas, maka zat warna termokromik jenis touch activated ini diaplikasikan dalam teknik pencapan dengan menggunakan binder khusus yang dapat berpolimerisasi pada $T$ kamar tanpa adanya pemanasawetan.

\section{METODA PENELITIAN}

Percobaan dikerjakan pada skala laboratorium di Laboratorium Pencapan dan Penyempurnaan Politeknik STTT Bandung. Aplikasi zat warna termokromik jenis touch activated dilakukan pada kain kapas dengan metode pencapan. Zat warna dan hasil pencapannya dianalisa menggunakan FTIR untuk mengetahui gugus fungsinya. Sifat-sifat hasil pencapannya dievaluasi, baik dari aspek perubahan warna, waktu retensi warna, dan juga ketahanan lunturnya terhadap pencucian serta kekakuan kainnya.

\subsection{Alat dan Bahan}

Alat dan bahan yang digunakan untuk percobaan adalah seperangkat alat 
pencapan (kasa screen dan rakel), kain kapas siap celup yang sudah melalui proses persiapan penyempurnaan, serta zat warna termokromik jenis touch activated dan binder (WB Screen Ink Kit 29C, LCR Hallcrest, UK) warna biru, merah, dan hitam. Zat warna dan binder yang digunakan diperoleh secara komersial dalam bentuk yang telah berupa campuran. Tidak ada tambahan zat pembantu lainnya dalam proses pencapan ini. Pada setiap percobaan dan pengujian dilakukan pengulangan sebanyak satu kali untuk memastikan adanya reproducibility. Alat-alat yang digunakan untuk pengujian dan evaluasi zat warna maupun hasil pencapannya adalah: spektrofotometer FTIR (Shimadzu type IR Affinity 1S), stopwatch, spektrofotometer cahaya tampak (Minolta CM3600d).

\subsection{Metoda}

Pasta cap dibuat dengan mencampurkan pasta zat warna termokromik jenis touch activated dan binder dengan perbandingan 1:1 dan dikeringkan pada suhu ruang. Kondisi proses tersebut ditentukan berdasarkan panduan teknis dari produsen. Karakterisasi gugus fungsi untuk zat warna dan kain hasil pencapan dilakukan dengan menggunakan spektrofotometer FTIR. Kain hasil pencapan dianalisis perubahan panjang gelombang warnanya dengan spektrofotometer cahaya tampak. Waktu retensi perubahan warna kembali setelah kain disentuh diuji dengan cara manual secara berulang dengan kelompok responden yang berbeda usia dan jenis kelamin agar diperoleh variasi karakteristik temperatur rata-rata alami dari responden. Pengujian ketahanan luntur warna terhadap pencucian berdasarkan standar SNI ISO 105C06:2010.

\section{HASIL DAN PEMBAHASAN}

\subsection{Proses Pencapan pada Kain Kapas}

Pencapan adalah suatu proses untuk mewarnai bahan tekstil dengan cara melekatkan zat warna pada kain secara tidak merata sesuai dengan motif yang diinginkan. Zat warna yang digunakan pada penelitian ini memiliki sifat hampir sama dengan zat warna pigmen konvensional. Zat warna termokromik tidak mempunyai gugus pelarut atau gugus fungsi yang dapat berikatan dengan serat (Wassem 
Ibrahim., 2012). Pada proses pencapan, zat warna termokromik jenis touch activated hanya menempel pada permukaan kain. Pencapan dilakukan dengan bantuan binder atau zat pengikat. Binder yang digunakan adalah W/B Screen binder termokromik jenis touch activated. Binder bekerja dengan cara memfasilitasi interaksi antara zat warna dengan serat. Interaksi antara zat warna dengan binder terjadi karena adanya polimerisasi binder yang membentuk lapisan film tipis (jaringan tiga dimensi) dan menahan zat warna termokromik pada permukaan bahan. Kuatnya ikatan atau penempelan zat warna termokromik pada serat sangat bergantung pada kuatnya ikatan antara lapisan film binder dengan seratnya.

Zat warna termokromik jenis touch activated yang digunakan pada penelitian ini berbentuk pasta. Berdasarkan informasi dari data teknis produk, pasta termokromik tersebut mengandung $52 \%$ air dan $48 \%$ padatan, dimana $40 \%$-nya adalah fase internal. Fase tersebut terdiri atas pengembang warna, warna sebelumnya dan pelarut yang mengontrol suhu perubahan warna, sedangkan $8 \%$ lainnya adalah dinding kapsul yang sebagian besar terdiri atas konstruksi melamin formaldehida berikatan silang. Rincian komposisi lebih lanjut tidak tersedia karena kerahasiaan industri. Pasta termokromik bersifat sangat peka terhadap suhu, sehingga berpotensi kehilangan warna pada suhu yang lebih tinggi. Karena itu, binder yang digunakan harus mampu berpolimerisasi pada suhu yang relatif rendah agar tidak merusak pigmen termokromik akibat dari suhu pemanasan yang tinggi. Binder yang digunakan pada pencapan ini berbentuk pasta putih yang mengandung ester akrilik karboksilat dan polimer butadiena (LCR Hallcrest, 2020). Pasta binder ini telah mengandung pengental dan bahan pembantu lainnya sehingga siap digunakan. Pembuatan pasta cap dilakukan dengan mencampurkan pasta zat warna termokromik dan binder dengan perbandingan 1:1. Metode pencapan yang dipilih yaitu pencapan langsung dimana pasta cap yang telah siap langsung dilekatkan pada kain kapas dengan bantuan rakel dan screen. Metode fiksasi yang digunakan adalah dengan sistem 
udara pada suhu ruang mengingat sifat zat warna termokromik yang rusak pada suhu $60{ }^{\circ} \mathrm{C}$ serta binder yang tidak memerlukan suhu tinggi untuk polimerisasi. Selanjutnya dilakukan pencucian menggunakan sabun lunak pada suhu kamar. Pencucian dimaksudkan untuk membersihkan zat warna yang tidak terikat dengan binder.

\subsection{Analisa Gugus Fungsi dengan FTIR}

Analisa gugus fungsi pada zat warna termokromik jenis touch activated menggunakan spektrofotometer FTIR menunjukkan bahwa zat warna tersusun atas komponen utama senyawa-senyawa organik aromatik yang mengandung gugus-gugus fungsi / substituen penguat warna organik. Gambar 3 (a, b, dan c) menunjukkan spektra IR dari tiga jenis warna zat warna termokromik (biru, merah, dan hitam) yang digunakan ada penelitian ini. Spektra FTIR juga mebandingkan puncak-puncak serapa yang terbentuk pada zat warna, kain kapas, serta hasil pencapan zat warna pada kain kapas.

Sebagaimana ditunjukkan ada Gambar 3, struktur molekul serat kapas adalah selulosa. Hal tersebut ditunjukkan dengan adanya grafik spektrum kapas (blanko) yang menunjukkan serapan maksimum dan kuat pada panjang gelombang $3649 \mathrm{~cm}^{-1}$ (menunjukan adanya gugus -OH). Pada puncak serapan panjang gelombang $2899 \mathrm{~cm}^{-1}$ menunjukkan adanya gugus - $\mathrm{CH}$ yang membuktikan adanya ikatan $\mathrm{C}-\mathrm{H}$ pada ujung struktur molekul, ikatan rangkap $\mathrm{C}=\mathrm{C}$ pada panjang gelombang 1506 $\mathrm{cm}^{-1}$ serta karbonil $-\mathrm{C}=\mathrm{O}$ pada panjang gelombang $1157 \mathrm{~cm}^{-1}$.

Puncak serapan pada masing-masing zat warna termokromik jenis touch activated berbeda-beda, namun menunjukkan hasil yang hampir sama. Hasil uji menunjukkan gugus fungsi $\mathrm{OH}$ dan $-\mathrm{CH}$, ikatan rangkap $\mathrm{C}=\mathrm{C}$ serta cincin aromatik $\mathrm{C}=\mathrm{C}$ pada masing-masing zat warna. Gugus fungsi tersebut, pada zat warna termokromik jenis touch activated biru masing-masing pada puncak serapan panjang gelombang $3649 \mathrm{~cm}^{-1}, 2924$ $\mathrm{cm}^{-1}, 1657 \mathrm{~cm}^{-1}$ dan $1508 \mathrm{~cm}^{-1}$. Puncak serapan panjang gelombang untuk zat warna termokromik jenis touch activated merah yaitu pada $3649 \mathrm{~cm}^{-1}$, $2931 \mathrm{~cm}^{-1}, 1654 \mathrm{~cm}^{-1}$ dan $1508 \mathrm{~cm}^{-1}$. Hasil pengujian untuk zat warna termokromik jenis touch activated hitam tidak menunjukkan adanya 
cincin aromatik $\mathrm{C}=\mathrm{C}$, namun terdapat gugus fungsi $-\mathrm{OH},-\mathrm{CH}$, dan ikatan rangkap $\mathrm{C}=\mathrm{C}$ dengan puncak serapan panjang gelombang masing-masing pada $3649 \mathrm{~cm}^{-1}, 2924 \mathrm{~cm}^{-1}$, dan 1651 $\mathrm{cm}^{-1}$.

Hasil pengujian gugus fungsi pada kain hasil pencapan dengan zat warna termokromik jenis touch activated berwarna merah, biru dan hitam juga menujukkan hasil yang hampir sama. Pada masing-masing spektrum hasil uji menunjukkan adanya gugus fungsi $\mathrm{CH}, \mathrm{C}=\mathrm{O}$ serta $-\mathrm{CO}$. Kain hasil pencapan merah dan hitam menunjukkan serapan puncak panjang gelombang yang sama, yaitu masingmasing gugus fungsi $-\mathrm{CH}$ pada 2916 $\mathrm{cm}^{-1}$ dan $2848 \mathrm{~cm}^{-1}$, serta $\mathrm{C}=\mathrm{O}$ dan CO pada panjang gelombang 1734 $\mathrm{cm}^{-1}$ dan $1165 \mathrm{~cm}^{-1}$. Gugus fungsi $-\mathrm{CO}$ $\mathrm{cm}^{-1}$ dan $\mathrm{C}=\mathrm{O} \mathrm{cm}^{-1}$ pada kain hasil pencapan biru, masing-masing pada panjang gelombang $1735 \mathrm{~cm}^{-1}$ dan $1166 \mathrm{~cm}^{-1}$.

Dengan

menggunakan sepektrofotometer FTIR, struktur kimia pasti dari zat warna yang digunakan ini tidak dapat dianalisis, tetapi hanya gugus fungsinya. Untuk memperoleh struktur kimia yang pasti, diperlukan pengujian lainnya yaitu NMR (Nuclear
Magnetic Resonance) dan juga analisa elemental (atom) untuk melihat kemungkinan zat warna berjenis anorganik. Namun demikian, adanya ikatan $\mathrm{C}=\mathrm{C}$ dan $\mathrm{C}=\mathrm{O}$ mengindikasikan adanya struktur cincin aromatic dan juga struktur kromofor zat warna pada zat warna yang dianalisa. Selain itu, adanya gugus fungsi $\mathrm{CO}$ mengindikasikan kecenderungan suatu cincin aromatis untuk dapat terbuka dan tertutup karena adanya rangsangan perubahan temperatur melalui sentuhan. Hasil karakterisasi dengan spektrofotometer FTIR ini baru mampu menunjukkan bahwa zat warna tersusun atas komponen utama senyawa-senyawa organik aromatik yang mengandung gugus-gugus fungsi / substituen penguat warna organik, namun tidak dapat dijelaskan dengan pasti, apakah zat warna mengandung logam atau senyawa anorganik atau tidak.

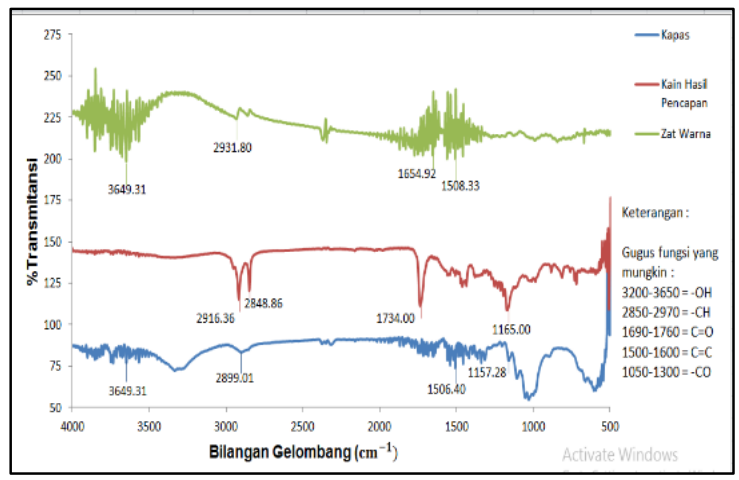

a) 


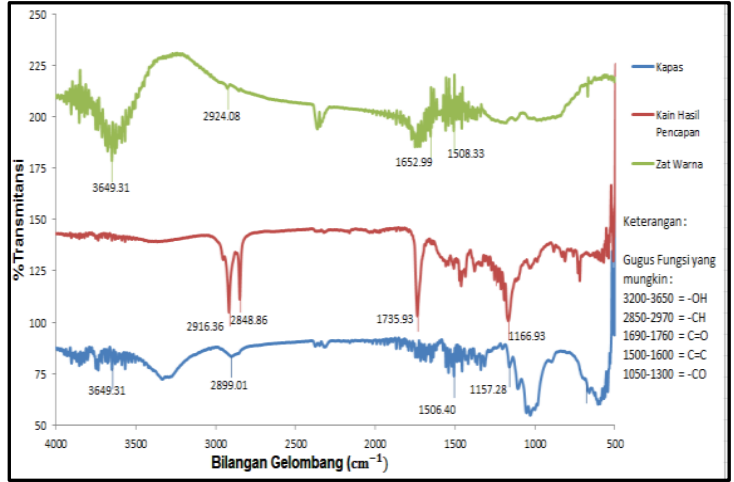

b)

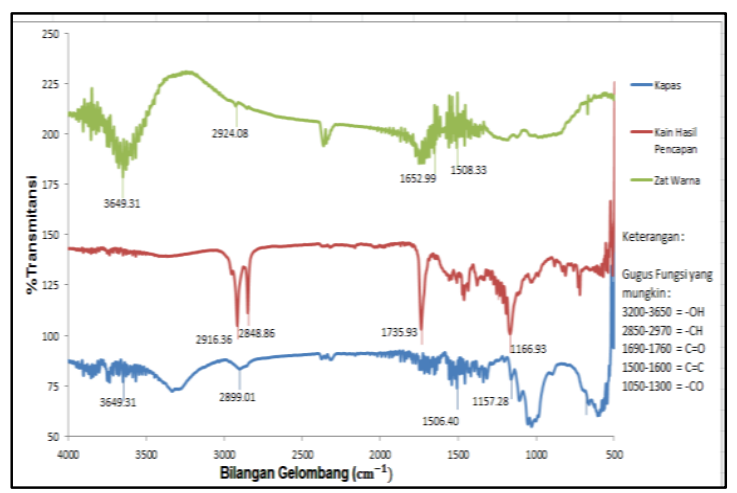

c)

Gambar 3. Kurva spektra FTIR zat warna termokromik jenis touch activated: (a) biru; (b) merah; dan (c) hitam

\subsection{Respon Perubahan Warna}

Pengujian respon perubahan warna bertujuan untuk mengetahui apakah zat warna termokromik bersifat reversibel atau irreversibel, serta untuk mengetahui apakah waktu perubahan warna kembali pada masing-masing kelompok responden relatif sama atau berbeda. Hasil pengujian dapat dilihat pada Gambar 4 di bawah ini. Dari Gambar tersebut dapat dilihat bahwa kain hasil pencapan setelah disentuh menghasilkan warna yang memudar, namun setelah dibiarkan selama waktu tertentu, warna dapat kembali terlihat seperti semula. Perubahan warna terjadi karena adanya perubahan struktur kimia pembentuk warnanya berubah menjadi bentuk isomernya sebagai bentuk respon terhadap rangsangan sentuhan (pada temperatur sentuhan) yang diberikan. Sentuhan yang diberikan dapat menaikkan temperatur pada kain sehingga menyebabkan perubahan struktur pada sistem kromofornya.

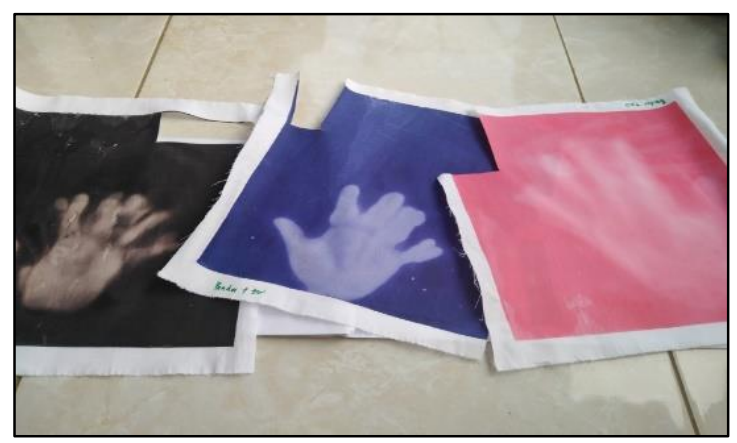

Gambar 0 Hasil Pengujian Respon

Warna Zat Warna Termokromik Jenis Touch Activated

Selain dengan cara visual, perubahan warna juga diidentifikasi melalui perubahan panjang gelombang maksimum kain hasil pencapan dengan zat warna termokromik jenis touch activated sebelum disentuh dan setelah disentuh. Perubahan panjang gelombang menunjukkan perubahan 
kenampakan warna, yang berarti terjadi perubahan struktur senyawa aromatik, sehingga cahaya yang jatuh pada obyek tersebut diserap dan dipantulkan pada panjang gelombang yang berbeda. Hasil pengujian menunjukkan bahwa zat warna biru, merah dan hitam sebelum disentuh, masing-masing terbaca memiliki panjang gelombang maksimum 600, 520 dan $580 \mathrm{~nm}$. Panjang gelombang tersebut tidak sesuai dengan spektrum warna yang telah dibakukan, terutama untuk hasil pencapan yang tampak berwarna hitam. Menurut teori, permukaan berwarna hitam biasanya tidak memiliki penyerapan efektif pada Panjang gelombang cahaya tampak, namun pada pengukuran dengan spektrofotometer hasil pencapannya terbaca memiliki Panjang gelombang $580 \mathrm{~nm}$. Hal tersebut kemungkinan besar karena warna yang tampak hitam tersebut sesungguhnya bukan betul-betul warna hitam, sehingga alatmembacanya berbeda dengan penglihatan secara visual oleh mata. Hal tersebut juga dapat dijelaskan dengan dasar teori yang menyatakan bahwa warna dan panjang gelombang dibagi menjadi dua, yaitu warna spektral dan warna non-spektral.
Warna spektral atau warna murni merupakan warna yang muncul dalam spektrum gelombang elektromagnetik dan merepresentasikan panjang gelombang tersendiri, sedangkan untuk warna non-spekral atau warna campuran adalah warna yang tidak ada dalam spektrum gelombang elektromagnetik (John W. Shipman, 2000). Dengan hasil pengujian tersebut, dapat diketahui bahwa zat warna termokomik yang digunakan merupakan warna-warna non-spektral. Data hasil pengujian juga menunjukkan bahwa nilai \%R kain hasil pencapan setelah disentuh mengalami kenaikan signifikan sebagai konsekuensi dari perubahan warna ke arah yang lebih muda. Untuk kain hasil pencapan berwarna biru, \%R berubah dari 6,63 menjadi 21,81 , untuk yang berwarna merah dari 19,94 menjadi 36,8 , sedangkan untuk yang berwarna hitam dari 5,69 berubah menjadi 11,48. Data-data \%R yang disajikan diambil dari grafik warna pada Panjang gelombang yang sama. Dalam pengukuran warna tersebut, perubahan nilai \%R juga seiring dengan adanya perubahan nilai kecerahan warna $\left(L^{*}\right)$ pada perubahan masing-masing zat warna. 
Berdasarkan analisis dari sumber literatur, perubahan warna pada zat warna termkromik jenis touch activated, secara kimia dapat diprediksi karena adanya penataan ulang struktur molekul, akibat struktur molekul zat warna yang tidak stabil. Sebagaimana ditunjukkan pada Gambar 5, struktur molekul (a) merupakan struktur molekul zat warna utama yang terdiri dari senyawa donor elektron yaitu COO- Ketika zat warna menerima rangsangan berupa sentuhan yang dapat menaikkan suhu, maka donor elektron tersebut akan menginduksi cincin sehingga cincin menjadi tertutup. Dengan penutupan cincin, warna tak nampak, sehingga yang dapat dilihat secara visual adalah adanya pemudaran warna. Struktur molekul mengalami perubahan kembali setelah zat warna melepaskan panas. Struktur molekul (b) dengan cincin tertutup dan bersifat tidak berwarna, dalam pelepasan panas yang mana menghasilkan donor proton beripa $\mathrm{H}^{+}$ akan menginduksi cincin, sehingga cincin kembali terbuka dan warna kembali muncul.

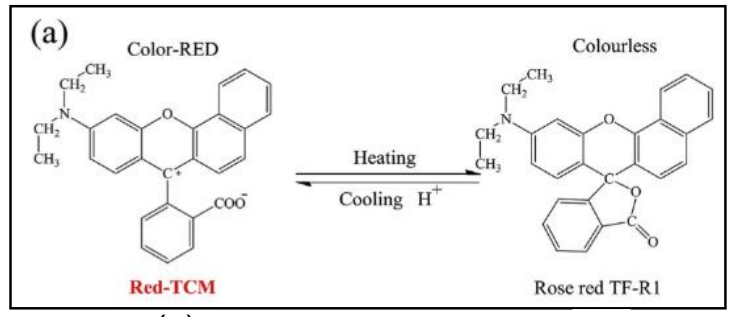

(a)

Sumber: Yangkai Zhang dkk, Fabrications of visual textile temperature indicators based on reversible thermochromic fibers, 2019.

Gambar 5. Prediksi Perubahan

Struktur Molekul Zat Warna

Termokromik Jenis Touch Activated

Warna Merah

\subsection{Waktu Retensi}

Waktu retensi adalah waktu yang dibutuhkan untuk suatu keadaan yang mengalami proses dan berubah menjadi keadaan lainnya. Pada penelitian ini, uji waktu retensi dilakukan untuk mengetahui lamanya warna kembali pada warna semula setelah mengalami perubahan karena adanya sentuhan. Pengujian waktu kembali warna yang dalam hal ini disebut waktu retensi dilakukan secara statistik melalui responden dengan latar belakang yang berbeda, yaitu sebanyak 12 orang dengan kelompok rentang usia dan jenis kelamin yang berbeda. Responden dibagi menjadi empat kelompok, yaitu: laki-laki muda 
(usia 5-15 tahun), laki-laki tua (16-35 tahun), perempuan muda (5-15 tahun) dan perempuan tua (16-35 tahun). Masing-masing kelompok responden terdiri dari tiga orang, sehingga waktu perubahan warna kembali merupakan hasil rata-rata. Gambar 6 menunjukkan waktu retensi zat warna yang dianalisis.

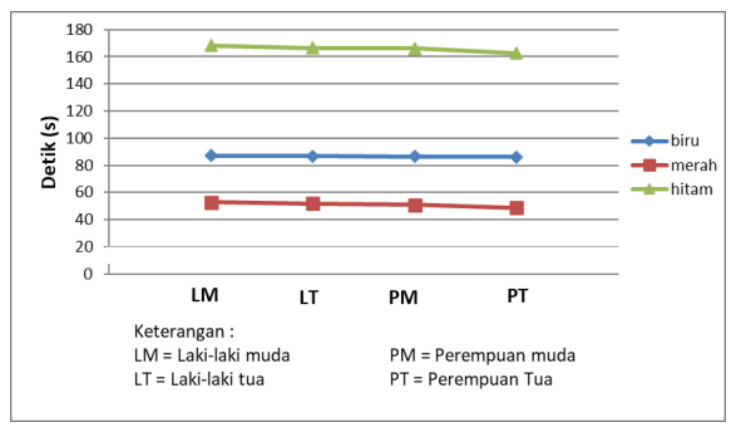

Gambar 6. Waktu retensi zat warna termokromik jenis touch activated biru, merah, dan hitam

Pengujian waktu retensi diolah secara statistik dengan metode chi-square melalui responden dengan latar belakang yang berbeda. Pemilihan responden berdasarkan jenis kelamin dan usia dilakukan untuk mengetahui karakteristik alami temperatur sentuhan, sebagai referensi untuk aplikasi yang lebih jauh, seperti sensor. Hasil perhitungan menunjukkan bahwa nilai chi-square hitung jauh lebih kecil dibandingkan dengan nilai chi-square tabel. Dengan demikian, dapat disimpulkan bahwa tidak ada pengaruh yang signifikan antara jenis kelamin dan usia pada waktu perubahan warna kembali.

\subsection{Ketahanan Luntur terhadap Pencucian}

3.6 Pengujian tahan luntur warna dilakukan berdasarkan standar SNI ISO 105-C06:2010. Hasil pengujian menunjukan bahwa kain mengalami luntur yang cukup signifikan (nilai staining scale 2-3) yang disebabkan oleh binder yang tidak berpolimerisasi maksimal serta proses pencucian yang dilakukan pada suhu ruang dan konsentrasi sabun yang kecil.

\section{KESIMPULAN}

Zat warna termokromk jenis touch activated tersusun atas gugus organik aromatik dan dapat diaplikasikan pada kain kapas dengan metode pencapan. Zat warna setelah mengalami sentuhan akan memudar menjadi warna yang lebih muda bahkan hingga tidak berwarna dan bersifat reversibel. Perbedaan usia dan jenis kelamin tidak berpengaruh secara signifikan pada waktu retensi. Ketahanan luntur warna terhadap pencucian kurang baik, 
sehingga zat warna tidak terlalu tepat digunakan untuk aplikasi pada pakaian sehari-hari atau yang memerlukan prose spewarnaan secara menyeluruh.

\section{UCAPAN TERIMA KASIH}

3. PT Surya Citra Pratama atas kerja sama dan support material untuk penelitian ini.

4. UP2M Politeknik STTT atas kesempatan dalam konteks kerja sama penelitian ini. 


\section{DAFTAR PUSTAKA}

1. Aitken D, Burkinshaw SM, Griffiths J, Towns AD. Textile applications of thermochromic systems. Review of Progress in Coloration. 1996; 26: 1-8.

2. Bamfield P. Chromic Phenomena: Technological Applications of Colour Chemistry. London, The Royal Society of Chemistry; 2001, 1-41.

3. Christie RM, dkk., Design Concepts For A Temperature Sensitive Environment Using Thermocromic Color. Heriot Watt University, 2007.

4. https://www.hallcrest.com, diakses pada 23 April 2020

5. Ibrahim, Waseem., An Investigation Into Textile Applications Of Thermochromic Pigments. Thesis phD. Heriot Watt University, 2012.

6. ISO 105 C06, Color Fastness to Domestic and Commercial Laundering.

7. Jhon W, Shipman. Introduction to color theory, 2000.

8. Khattab T, dkk., Smart textile framework: Photochromic and fluorescent cellulosic fabric printed by strontium aluminate pigment, Carbohydrate Polymers, 195 (2018) 143-152.

9. Kooroshina, Marjan. Leuco Dye Based Thermochromic Inks : Recipes As A Guide For Designing Textile Surfaces. Swedish School Of Textiles At University Of Boras. 2013.

10. Pira, S. (2013). Thermochromic inks and reducing houseold food waste. www.wrap.org.uk

11. Talvenma P., Chromic and Conductive Materials, In Intelligent Textile and Clothing, ed. Mattila HR, Cambrdge, UK, Woodhead, Chapter II, 2006.

12. Tang, S.L.P. An Overview of Smart Technologiest For Clothing Design And Engineering. School of Textile \& Design. 2006.

13. Zhang, Y., Hu, Z., Xiang, H., dkk. (2019). Fabrication Of Visual Textile Temperature Indicators Based On Reversible Thermochromic Fibers.

14. Zhu, X., Liu, Y., Dong, N., \& Li, Z. (2017). Fabrication and characterization of reversible thermochromic wood veneers. Scientific reports; www.nature.com 